Special issue of the 2nd International Conference on Computational and Experimental Science and Engineering (ICCESEN 2015)

\title{
Radiation Dose in Dental Radiology
}

\author{
Ü. KARA ${ }^{a, *}$, D. YILDIRIM ${ }^{b}$ AND I. AKKURT ${ }^{c}$ \\ ${ }^{a}$ Suleyman Demirel University, Vocational School of Healt Services, Isparta, Turkey \\ ${ }^{b}$ Suleyman Demirel University, Faculty of Dentistry, Isparta, Turkey \\ ${ }^{c}$ Suleyman Demirel University, Physics Department, Isparta, Turkey
}

\begin{abstract}
The radiation is used in a wide range of medical fields, in diagnosis and treatment. Certain body parts, like thyroid, are more specifically affected by exposure to different types of radiation sources. The thyroid is highly susceptible to radiation carcinogenesis and exposure to ionising radiation is the only established cause of thyroid cancer. In this study, we have examined radiation doses measured during diagnosis which used dental panoramic radiography. The measurement has been performed in the Suleyman Demirel University, at PlanmecaProMax 3D (cone beam) imaging unit. The device operates at $66-70 \mathrm{kV}, 8-10 / 22 \mathrm{~mA} / \mathrm{s}$.
\end{abstract}

DOI: 10.12693/APhysPolA.130.407

PACS/topics: 87.50.yk, 87.57.uk

\section{Introduction}

Applications of radiation in medicine include diagnosis and treatment. For this study was selected a facility which frequently uses panoramic shots for the purpose of diagnosis in dentistry and dental radiography. Part of the x-rays radiation used in dentistry diagnostics carries a risks of triggering the thyroid cancer and brain tumors (meningioma tumors). However, there is no a clear opinion on this issue, which made us to carry out this work. Doses received during these operations might be caused by the device directly or may be in the form of light scattering or leakage. Such doses of scattering or direct exposure can create a threat to both staff and patients. The x-rays used during the imaging of the teeth and jaw can also affect other tissues in the vicinity. Thus thyroid or brain can be damaged. The possible link between pituitary or thyroid and the risk of low birth weight infants due to maternal exposure to low levels of dental x-ray is a recent example of a continuing scrutiny of potential radiation hazards from diagnostic imaging [1]. In dental radiography, the part of the head that receives the greatest dose is the skin in the area where the x-rays enter. A recent study was performed at the Department of Diagnostic Sciences at the University of North Carolina School of Dentistry in Chapel Hill, using a realistic head phantom and state-of-the-art imaging systems [2].

\section{Materials and methods}

In this study, we have worked at Oral and Maxillofacial Radiology department of Suleyman Demirel University, at Faculty of Dentistry, which has got a Planmeca Pro Max 3D (cone beam) imaging unit (Fig. 1) used for oral radiology. The main parameters for Planmeca Pro Max 3D (cone beam) imaging unit are listed

\footnotetext{
*corresponding author; e-mail: umitkara@sdu.edu.tr
}

in Table I. We have repeated the measurements for one month using Polimaster PM-1621 x-ray and gamma-ray radiation personal dosimeter (Table II). During the procedures we have been wearing a lead apron. The mean doses received by patients, who had surgery performed under Planmeca Pro Max 3D (cone beam) imaging unit at $66-70 \mathrm{kV}, 8-10 / 22 \mathrm{~mA} / \mathrm{s}$, were recorded. The measurements were taken (Fig. 2) during imaging at distances of $71 \mathrm{~cm}, 128 \mathrm{~cm}, 238 \mathrm{~cm}, 278 \mathrm{~cm}$ and $326 \mathrm{~cm}$ away from the operating table. Averaged radiation dose values measured during this period for different patients are given in Figs. 3-5. We were recording radiation doses of oral radiology patients.
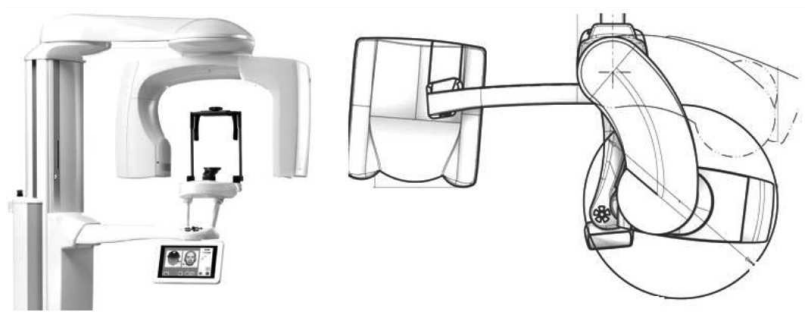

Fig. 1. Dental x-ray unit used in the study.
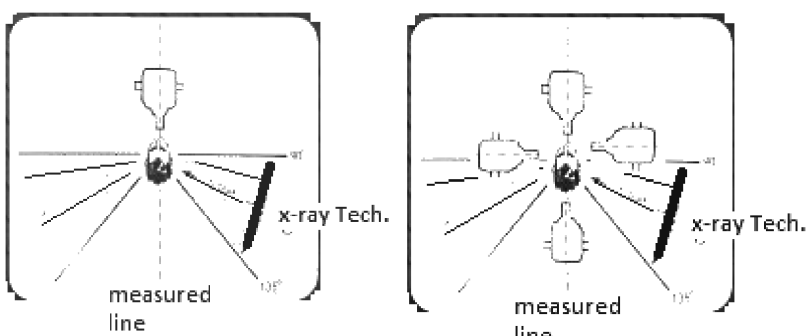

line

Fig. 2. Measurement direction line relative to dental x-ray unit. 


\section{TABLE I}

Features of dental x-ray unit.

\begin{tabular}{c|c}
\hline \hline Width & $116 \mathrm{~cm}$ \\
Depth & $137 \mathrm{~cm}$ \\
Height & $161-239 \mathrm{~cm}$ \\
Weight & $131 \mathrm{~kg}$ \\
Anode voltage & $50-90 \mathrm{kV}$ \\
Anode current & $1-12 \mathrm{~mA}$ \\
Focal spot & $0.6 \mathrm{~mm}$ fixed anode \\
Image detector & Flat panel \\
Image acquisition & $210 / 360$ degree rotation \\
Scan time & $9-40 \mathrm{~s}$ \\
Reconstruction time & $2-55 \mathrm{~s}$
\end{tabular}

TABLE II

Features of personal dosimeter PM-1621.

\begin{tabular}{c|c}
\hline \hline Detector & GM tube \\
\hline DER measurement range & $0.1 \mu \mathrm{Sv} / \mathrm{h}-100 \mathrm{mSv} / \mathrm{h}$ \\
\hline Dose rate accuracy & $\begin{array}{c} \pm(15+0.0015 / H+0.01 H) \% \\
\text { (in range } 0.1 \mu \mathrm{Sv} / \mathrm{h}-0.1 \mathrm{~Sv} / \mathrm{h}, \\
\text { where } H-\text { dose rate in } \mathrm{mSv} / \mathrm{h})\end{array}$ \\
\hline DE measurement range & $\begin{array}{c}01.01 \mu \mathrm{Sv}-9.99 \mathrm{~Sv} \\
(1 \mu \mathrm{R}-999 \mathrm{R})\end{array}$ \\
\hline Dose accuracy & $\begin{array}{c}(15 \%) \mathrm{range} 1 \mu \mathrm{Sv}-9.99 \mathrm{~Sv} \\
(100 \mathrm{R}-999 \mathrm{R}))\end{array}$ \\
\hline $\begin{array}{c}\text { Energy range } \\
\text { to 0.662 MeV }\left({ }^{137} \mathrm{Cs}\right)\end{array}$ & \begin{tabular}{c}
$10.0 \mathrm{KeV}-20.0 \mathrm{MeV}$ \\
\hline $\begin{array}{c}\text { Survive after momentary influence } \\
\text { of maximum permissible gamma } \\
\text { radiation within } 5 \text { min }\end{array}$
\end{tabular} \\
\end{tabular}

\section{Results}

Dependences of the radiation dose on the distance from the x-ray tube for different values of the x-ray tube voltage and current are shown in Figs. 3-5. These doses vary somewhat from different machines, however the figures listed below are probably within the actual amounts received by the patient.
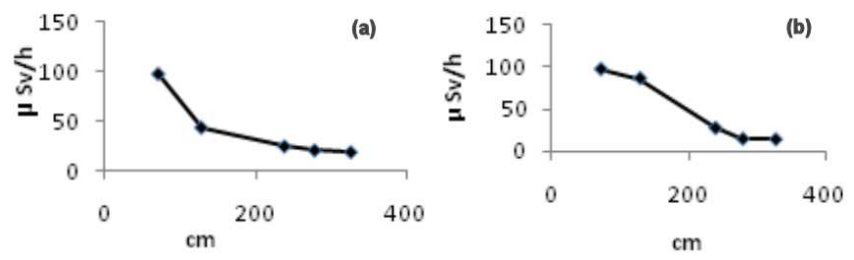

Fig. 3. Radiation dose as a function of distance from the x-ray tube at (a) $66 \mathrm{kV}, 8 \mathrm{~mA}$, (b) $66 \mathrm{kV}, 9 \mathrm{~mA}$.

\section{Discussion}

Children of developmental age are the group which is most sensitive to radiation. Commonly in recent years, especially with children, during orthodontic (teeth and jaw correction) treatment, dental x-ray is requested at each control. Patients are less exposed to radiation when
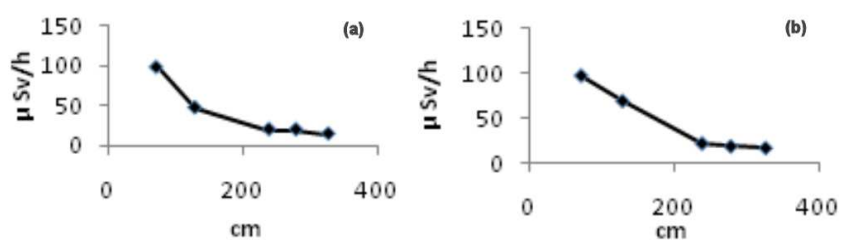

Fig. 4. Same as in Fig. 3 at (a) 68 kV, 8 mA, (b) 68 kV, $9 \mathrm{~mA}$.
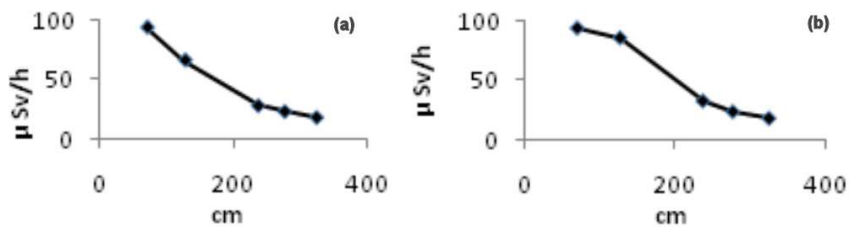

Fig. 5. Same as in Fig. 3 at (a) $70 \mathrm{kV}, 9 \mathrm{~mA}$, (b) $70 \mathrm{kV}$, $10 \mathrm{~mA}$.

a small dental image is taken, but the exposure is much higher when a panoramic dental image is made. Guidelines and selection criteria for the appropriate use of dental radiographs have been published by professional societies and can be used to assist the dentist in this process $[3,4]$.

\section{Conclusions}

The procedures aimed at radiation protection of patients are essential, especially during the x-ray imaging. Dentists and dental technicians are more frequently seen to have thyroid cancer. Each dentist, has got small-size dental x-ray machine, and therefore dentists and dental technicians are exposed to radiation. Patients and employees should be provided with such thyroid protective radiation shields as lead aprons. Especially for children, during dental imaging, the thyroid gland should be protected from x-ray beam. In conclusion, justification of dental radiograph selection and optimization of exposure parameters with the ALARA principle in mind should be employed for every patient in the dental practice.

\section{References}

[1] P.P. Hujoel, A.M. Bollen, C.J. Noonan, M.A. del Aguila, JAMA-J. Am. Med. Assoc. 292, 1019 (2004).

[2] J.B. Ludlow, L.E. Davies-Ludlow, S.C. White, J. Am. Dent. Assoc. 139, 1237 (2008).

[3] American Dental Association Council on Scientific Affairs, J. Am. Dent. Assoc. 137, 1304 (2006).

[4] European Commission. Radiation Protection, European guidelines on radiation protection in dental radiology: the safe use of radiographs in dental practice, Issue No. 136, 2012. 